clear how to decide in which cases operation is indicated. The practitioner in referring a case to a specialist must be very careful to explain to the parents that operation is unlikely to be necessary, as so many parents will demand an operation for cosmetic reasons if they hear that one can be done, and it is never advisable in this condition on such grounds alone.

This supplement is well worth buying in its own right even if one does not possess the main volumes.

\section{RHEUMATIC DISEASES, RHEUMATISM AND ARTHRITIS}

By Heinrich G. Brugsch, M.D., F.A.C.P. Pp. xiv +330 , with 58 illustrations. London: Pitman Medical Publishing Co. 1957. 8os.

This book owes much to the author's wide knowledge of his subject and to the help which he has received and acknowledged in putting it in print. The historical, anatomical and physiological sections, often tedious in a work of this nature, have been condensed. The pathological sections are concise and adequate. The longest single section, as one might expect, is on therapy which is well covered, as are laboratory procedures and X-ray examination. Rheumatic fever and the major arthritides are dealt with in five chapters, the lesser arthritides and the collagen diseases are covered separately.

This is essentially a readable and practical work, the general information should be sufficient for student and postgraduate alike. A comprehensive bibliography at the end of each chapter should be of great help to the student seeking fuller knowledge.

\section{L.A.H.}

\section{HISTOLOGY}

By A. W. HaM, M.B., F.R.S.C. Third edition. Pp. xv +894 , with 582 illustrations. London: Pitman Medical Publishing Co. Ltd. 1957. 8os.

This text-book has established itself in a very short space of time (the first edition appeared in r950) as perhaps the best introduction to the study of the microscopical structure of human and mammalian tissues for the medical student. An outstanding characteristic has been the way in which the most recent advances in technique and interpretation have been explained, with a full appreciation of the difficulties which an elementary student will have in approaching an unfamiliar subject.

This new edition differs considerably from the two previous editions since what the author rightly describes as ' a major revolution in histology' has been brought about by the recent intensive exploitation of the high resolving power of the electronmicroscope for the examination of animal tissues. A short but excellent account of the basic principles of the electron-microscope and of the technical methods which have been developed for its use in histology has been added. In nearly every chapter of the book the results of these methods have been described, and there are few in which important advances cannot be reported. These are often the solutions to problems which have been matters of long-standing controversy, such as the nature of the lining of pulmonary alveoli, of synaptic junctions, or the relationship, syncytial or non-syncytial, between cardiac muscle fibres. A large number of electron-micrographs are used for illustration, and the author may be congratulated on the co-operation he has recieved from many colleagues in bringing together so excellent a collection.

Although electron-microscopy accounts for the major changes in this edition, other advances have not been neglected. The attention given to the problem of the transplantation of tissues is welcome, and chapters such as those dealing with tissue culture, blood cells, calcification and several other subjects have been rewritten or substantially modified. It is possible that too little space is given to recent histochemical investigations and their critical interpretation, but it is obvious that in a field so wide it is impossible to deal with every aspect in the detail which any reader might wish. In addition to its obvious value to the undergraduate student, there is no doubt that this book will have a wide appeal, since, with the classified lists of references, any chapter is an excellent introduction to a wider survey of some special aspect of the field of histology such as a post-graduate or research worker would require.

\section{PSYCHOSOMATICS}

\section{A Series of Five Lectures}

Edited by JohanN BoorJ. Pp. I25, with 2 illustrations. London: Cleaver-Hume Press Ltd. 1957. 24 s.

This is a collection of five papers which developed from a meeting of Dutch psychiatrists and physicians in Amsterdam, held to discuss and publish a statement on psychosomatic medicine as it exists in the Netherlands today. In this compendium of views we have a picture of the national character of the subject as well as a remarkably clear evaluation of what psychosomatics can contribute to medicine as a whole.

The authors are men of wide experience and high academic status whose names will be well known to readers of Folia Psychiatrica. Professor Prick opens with an overview of psychosomatic medicine and discusses its possibilities and its limitations. Drs. Groen, Bastiaan and Van der Valk then give an excellent analysis of syndrome shift and suppression, and Professor Van der Horst follows with an analysis of motivation-inevitably the basic factor in any psychodynamic theory-and discusses this in the general context of anthropology. 